University of Warwick institutional repository: http://go.warwick.ac.uk/wrap This paper is made available online in accordance with publisher policies. Please scroll down to view the document itself. Please refer to the repository record for this item and our policy information available from the repository home page for further information.

To see the final version of this paper please visit the publisher's website. Access to the published version may require a subscription.

Author(s): Graham Ladds, Sevasti Zervou, Manu Vatish, Steven Thornton1 and John Davey

Article Title: Regulators of $G$ protein Signalling proteins in the human myometrium

Year of publication: Forthcoming

Link to to published version:

Publisher statement: None 


\section{Regulators of G protein Signalling proteins in the human myometrium}

Graham Ladds $^{1}$, Sevasti Zervou ${ }^{2}$, Manu Vatish ${ }^{1}$, Steven Thornton ${ }^{1}$ and John Davey ${ }^{1}$

Clinical Sciences Research Institute

University of Warwick Medical School

UHCW Campus

Clifford Bridge Road

Coventry CV2 2DX, UK

2 Department of Biological Sciences

University of Warwick

Coventry CV4 7AL, UK

* Author for correspondence

Warwick Medical School

University of Warwick

Coventry CV4 7AL, UK

Tel: $+44(0) 2476528361$

Fax: $+44(0) 2476523701$

Graham.ladds@warwick.ac.uk 


\section{Abstract}

The contractile state of the human myometrium is controlled by extracellular signals that promote relaxation or contraction. Many of these signals function through $\mathrm{G}$ proteincoupled receptors at the cell surface, stimulating heterotrimeric $\mathrm{G}$ proteins and leading to changes in the activity of effector proteins responsible for bringing about the response. $G$ proteins can interact with multiple receptors and many different effectors and are key players in the response. Regulators of G protein signalling (RGS) proteins are GTPase activating proteins for heterotrimeric $\mathrm{G}$ proteins and help terminate the signal. Little is known about the function of RGS proteins in human myometrium and we have therefore analysed transcript levels for RGS proteins at various stages of pregnancy (non-pregnant, preterm, term non-labouring, term labouring). RGS2 and RGS5 were the most abundantly expressed isolates in each of the patient groups. The levels of RGS4 and RGS16 (and to a lesser extent RGS2 and RGS14) increased in term labouring samples relative to the other groups. Yeast two-hybrid analysis and co-immunoprecipitation in myometrial cells revealed that both RGS2 and RGS5 interact directly with the cytoplasmic tail of the oxytocin receptor, suggesting they might help regulate signalling through this receptor.

Key words: G protein-coupled receptors; labour; myometrium; RGS proteins 


\section{Introduction}

Initiation of labour involves a change from quiescence to regular, forceful uterine contractions. The change is mediated by hormonal, metabolic and intracellular signalling, but the regulatory mechanisms underlying this process are poorly understood. Information relating to these mechanisms is essential to providing a better understanding of disorders associated with human parturition, such as pre-term labour (Lopez-Bernal and TambyRaja, 2000). Many of the signalling pathways that regulate contraction and relaxation of myometrial cells involve G protein-coupled receptors (Europe-Finner et al., 1997; Plested and Lopez-Bernal, 2001). In the unstimulated state, the receptor is associated with a heterotrimeric complex of $G \alpha, G \beta$ and $G \gamma$ subunits in which the $G \alpha$ subunit is bound to GDP. Receptor activation stimulates exchange of GDP for GTP, releasing the G $\alpha$-GTP and G $\beta \gamma$ subunits to activate downstream effectors that bring about changes in cell behaviour. For example, the oxytocin receptor functions via G proteins that activate phospholipase $\mathrm{C}$, thereby increasing inositol trisphosphate (IP3) production, leading to increases in intracellular calcium, triggering muscle contraction (Blanks and Thornton, 2003). The receptors for prostaglandins, vasopressin and corticotrophinreleasing factor $(\mathrm{CRF})$ also act via $\mathrm{G}$ protein-coupled receptors and $\mathrm{G}$ proteins. As many $\mathrm{G}$ protein-coupled receptors can interact with more than one $\mathrm{G}$ protein, and many $\mathrm{G}$ proteins can activate more than one type of effector protein, the G proteins play a pivotal role in integrating the stimulatory and inhibitory signals that regulate contractility. 
G protein signalling ceases when G $\alpha$-GTP hydrolysis returns the heterotrimer to its inactive state. The slow intrinsic rate of GTP hydrolysis by G $\alpha$ proteins is regulated by interactions with a specific subfamily of GTPase-activating proteins (GAPs) known as Regulators of G protein Signalling or RGS proteins (Ross and Wilkie, 2000; Hollinger and Hepler, 2002; Xie and Palmer, 2007). Since their discovery in Caenorhabditis elegans (Koelle and Horvitz, 1996) and Saccharomyces cerevisiae (Dohlman et al., 1996), over 30 different RGS proteins have been identified in mammals, many with spatiotemporal-specific expression (Abramow-Newerly et al., 2006; Xie and Palmer, 2007).

There have been several studies into the ability of RGS proteins to regulate contraction in cardiomyocytes (Tamirisa et al., 1999; Mittmann et al., 2002; Snabaitis et al., 2005; Hao et al., 2006), vascular smooth muscle cells (Tang et al., 2003) and intestinal smooth muscle (Hu et al., 2008) but little is known about their role in myometrium. Microarray analyses have detected expression of several RGS transcripts in human myometrium and a recent study found that expression of RGS12 was upregulated at labour (O'Brien et al. 2008). Earlier studies from Soloff and colleagues showed that RGS2 mRNA levels increased in cultured human myometrial cells following stimulation with oxytocin (Park et al., 2002) while RGS2 transcription in rats increased dramatically during pregnancy before being down-regulated at term (Suarez et al., 2003). However, no investigation of the role of RGS2 was undertaken in either system. 
To initiate a more complete understanding of RGS expression in human myometrium, we used semi-quantitative polymerase chain reaction (PCR) to analyse transcript levels for all of the major RGS proteins at various stages of pregnancy (non-pregnant, preterm, term non-labouring, term labouring). Transcripts for many of the RGS proteins were present at low level and did not vary throughout pregnancy, although the levels of RGS4 and RGS16 (and to a lesser extent RGS2 and RGS14) increased in the term labouring samples. RGS2 and RGS5 were the most abundantly expressed isolates in each of the patient groups and we sought to further investigate potential roles for these two RGS proteins in human myometrium. Yeast two-hybrid analysis and co-immunoprecipitation experiments in primary myometrial cells revealed that both RGS2 and RGS5 interact directly and specifically with the cytoplasmic tail of the oxytocin receptor. Our results suggest a potential role for RGS proteins in regulating signalling in the human myometrium. 


\section{Materials and Methods}

\subsection{Subject criteria and selection.}

All procedures were conducted within the guidelines of The Declaration of Helsinki and were subject to local ethical approval (REC-05/Q2802/107). Myometrial samples were collected with informed written consent from the following groups of women: (i) nonpregnant (aged 38-48 years) undergoing hysterectomy for dysmenorrhoea (ii) preterm pregnant women (aged 20-30 years) prior to the onset of labour ("preterm") (iii) term pregnant women prior to labour ("term, non-labouring") (iv) term pregnant women following the onset of labour ("term, labouring"). Labour was defined as regular contractions ( $<3$ min apart) plus membrane rupture and cervical dilation $(>3 \mathrm{~cm})$ with no augmentation. Samples were taken from the upper edge of a lower segment incision at Caesarean section from women without underlying disease, for fetal distress, breech presentation, previous section, placental praevia, maternal request or failure to progress. Non-pregnant biopsies were taken from the upper third of the uterine body, approximately $5 \mathrm{~mm}$ away from endometrial or serosal surfaces, immediately after hysterectomy. Tissue was snap-frozen in liquid nitrogen and stored at $-80^{\circ} \mathrm{C}$.

\subsection{RNA analysis}

Total RNA was extracted from frozen myometrial biopsies (Total RNA Isolation Kit RNAEasy; Promega, Southampton, UK) according to the manufacturer's instructions. RNA was reverse transcribed into complementary DNA (cDNA) for use as a template for amplification by the polymerase chain reaction (PCR) by using 500 ng total RNA 
samples, random hexamers $\left(\mathrm{N}_{6}\right)$ (Pharmacia Amersham Life Sciences, Little Chalfont, UK) and 10 IU/ $\mu 1$ RNase $\mathrm{H}^{-}$Reverse Transcriptase Superscript II (Gibco BRL Life Technologies, Paisley, UK). Complementary DNA from the reaction was used in the amplification reaction. PCR was carried out with oligonucleotide primers specific for each RGS. The sequence for each pair of sense and anti-sense primers, corresponding to the open reading frame of each of human RGSs (RGS1 to RGS16) and the size of the expected PCR product are listed in Table 1. We did not screen for RGS8 as it is brain specific (Koelle and Horvitz, 1996; Saitoh et al., 1997), and RGS15 is a splice variant of RGS3 (Druey et al., 1996; Chatterjee et al., 1997).

PCR was performed in $25 \mu 1$ reactions using $10 \mu \mathrm{Ci} / \mu 1\left[{ }^{32} \mathrm{P}\right]$-labelled $\alpha$-dGTP and $5 \mathrm{IU} / \mu \mathrm{l}$ TAQ DNA polymerase (Gibco BRL Life Technologies). Amplifications were carried out as follows: an initial denaturation step of $5 \mathrm{~min}$ at $94^{\circ} \mathrm{C}$ followed by 27 to 30 cycles of denaturation at $94^{\circ} \mathrm{C}$ for $1 \mathrm{~min}$, annealing at $55^{\circ} \mathrm{C}$ to $60^{\circ} \mathrm{C}$ for $1 \mathrm{~min}$, and elongation at $72^{\circ} \mathrm{C}$ for $1 \mathrm{~min}$, followed by a final extension at $72^{\circ} \mathrm{C}$ for $10 \mathrm{~min}$. PCR products were separated by electrophoresis on a $6 \%$ polyacrylamide gel and the dried gel exposed to Xray film (Fuji Photo Film Co. Ltd., Tokyo, Japan) or to a phosphorimager screen (Molecular Dynamics, Pharmacia Amersham Life Sciences, Little Chalfont, UK) for quantification purposes. Radioactivity peaks for each product were determined using ImageQuant (IQ) (Molecular Dynamics, Pharmacia Amersham Life Sciences).

PCR products were purified using the Geneclean II Kit (Amersham, Luton, UK) and ligated into the EcoRI restriction site of pCR-TOPO vector (Invitrogen BV, Croningen, 
Netherlands) using TOPO TA Cloning Kit (Invitrogen BV). The vector was used to transform DH5 $\alpha$ strain of Escherichia coli and plasmids isolated using the QIAprep Spin Plasmid Kit (Qiagen, Crawley, Sussex, UK). PCR products obtained for human RGS1 to RGS16 were sequenced by the di-deoxynucleotide method with double-stranded DNA as template.

\subsection{Expression analysis}

All PCR reactions were performed in triplicate. The amount of PCR product for each RGS mRNA was compared to the product obtained using primers for calponin. The mRNA levels of calponin do not change with or throughout pregnancy and calponin was used as a housekeeping gene for normalisation of the cDNA input (Brodt-Eppley and Myatt, 1999; Moore et al., 1999). In order to validate the semi-quantitative nature of the technique, PCR reactions were also performed with $50 \%$ of the original cDNA concentration as template. Results are expressed as mean \pm SE. Comparison between sample sets was by one-way ANOVA with Tukey's multiple comparison test.

Differences were considered significant at $P<0.05$ level. All analysis was performed with GraphPad Prism version 4.03 (GraphPad Software Inc, San Diego, CA, USA).

\subsection{Yeast two-hybrid screening}

The AH109 Saccharomyces cerevisiae strain and vectors were supplied with the Matchmaker yeast two-hybrid kit (BD Biosciences Clontech, Oxford, UK). The region encoding the C-terminal cytoplasmic domains of the oxytocin receptor (from residue $\mathrm{Gly}^{334}$ ) and the CRF receptor $1 \mathrm{a}$ (from residue $\mathrm{Val}^{370}$ ) were amplified by PCR and cloned 
into pGBKT7 to produce in-frame translational fusions to the GAL4 Binding Domain. The coding regions for full length RGS1, RGS2 and RGS5 were amplified by PCR using the primers in Table 1 and cloned into pGADT7 to produce in-frame translational fusions to the GAL4 Activation Domain. Two-hybrid assays were carried out following sequential transformations of AH109 with pGBKT7-based plasmids and then pGADT7based plasmids. Co-transformants were maintained on MM (a defined minimal medium lacking leucine and tryptophan) and immunoblotting was used to confirm that the various fusion proteins were expressed. Cell concentrations were determined using a Coulter Channelyser (Beckman-Coulter, Luton, UK). Experiments to investigate interactions and protein expression were repeated at least three times with different isolates.

\subsection{Protein analysis in myometrial cells}

Myometrial tissue samples were digested at $37^{\circ} \mathrm{C}$ for $30 \mathrm{~min}$ in Dulbecco's Modified Eagle's Medium (DMEM) containing $1 \mathrm{mg} / \mathrm{ml}$ collagenase $1 \mathrm{~A}$ and $1 \mathrm{mg} / \mathrm{ml}$ collagenase XI (Sigma-Aldrich, Poole, UK). Cells were dissociated by triturating through a Pasteur pipette, filtered through a $45-\mu \mathrm{m}$ filter and further digestion stopped by adding $10 \%$ fetal calf serum (FCS) (Invitrogen Life Technologies, Paisley, UK) in DMEM. Following centrifugation (450 g for $15 \mathrm{~min}$ ), cells were resuspended in DMEM supplemented with $10 \%$ FCS, L-glutamine, penicillin-streptomycin $(100 \mathrm{U} / \mathrm{ml})$ and amphotericin B (2 $\mu \mathrm{g} / \mathrm{ml}$ ) and grown at $37^{\circ} \mathrm{C}$ in $5 \% \mathrm{CO}_{2}$. The purity of myocycte cultures was routinely assessed using $\alpha$-actin and calponin monoclonal antibodies as described previously (Tribe et al., 2000). All experiments in this study were performed with myometrial cells between 1 and 4 passages. Cells were resuspended in lysis buffer (25 mM Hepes pH7.5, $150 \mathrm{mM}$ 
$\mathrm{NaCl}, 3 \mathrm{mM}$ EDTA, $3 \mathrm{mM}$ EGTA, $1 \mathrm{mM}$ sodium orthovanadate, $50 \mathrm{mM} \mathrm{NAF}, 0.5 \% \mathrm{w} / \mathrm{v}$ Triton X-100) and insoluble material removed by centrifugation $(10,000 \mathrm{~g}$ for $15 \mathrm{~min})$. Precipitating antibody, or preimmune serum, was added and incubated at $4^{\circ} \mathrm{C}$ for $4 \mathrm{~h}$ before addition of protein G-Sepharose beads (Sigma-Aldrich). The mixture was incubated with rotation overnight at $4^{\circ} \mathrm{C}$. Beads were collected by centrifugation, washed, and the proteins eluted in sample buffer $(50 \mathrm{mM}$ Tris- $\mathrm{HCl} \mathrm{pH}$ 6.8, $8 \% \mathrm{v} / \mathrm{v}$ glycerol, $1 \%$ $\mathrm{w} / \mathrm{v}$ SDS and $2 \% \mathrm{v} / \mathrm{v} \beta$-mercaptoethanol) before being resolved by SDS-PAGE on a $12 \%$ polyacrylamide gel. Following separation, proteins were transferred to a polyvinylidene fluoride (PVDF) membrane (Bio-Rad, Hemel Hempstead, Hants, UK) soaked in Towbin buffer (25 mM Tris, $192 \mathrm{mM}$ glycine, 0.1\% w/v SDS, 10\% v/v methanol) using a SemiPhor Transfer Dry Blotting Unit (Hoefer Scientific Instruments, San Francisco, CA, USA) run at $65 \mathrm{mV}$ for $30 \mathrm{~min}$. Non-specific binding sites were blocked using 5\% lowfat milk powder in TST (10 mM Tris- $\mathrm{HCl} \mathrm{pH} 7.5,100 \mathrm{mM} \mathrm{NaCl}$ and $0.05 \% \mathrm{v} / \mathrm{v}$ Tween20) for 90 min. Antibodies were used according to their manufacturer's instructions; rabbit anti-CRFR1, rabbit anti-OTR, rabbit anti-RGS2 and goat anti-RGS5 (Santa Cruz Biotechnology, Santa Cruz, CA, USA), HRP-conjugated donkey anti-sheep (SigmaAldrich) and HRP-conjugated donkey anti-rabbit (Amersham plc, Little Chalfont, UK). The blot was incubated with primary antibody for $1 \mathrm{~h}$, washed, and incubated with the secondary antibody for $1 \mathrm{~h}$. Chemiluminescent signals were detected using the ECL detection reagent (Amersham plc). 


\section{Results}

\subsection{Expression of RGS1-RGS16 mRNA in human myometrium}

Semi-quantitative RT-PCR was used to analyse RGS mRNA expression in different samples of human myometrium, and the results compared to the mRNA levels of calponin (Fig. 1). The mRNA level of calponin do not change with or throughout pregnancy (Brodt-Eppley and Myatt, 1999; Moore et al., 1999), providing an appropriate mechanism to control or indicate standardising the study. Nucleotide sequencing confirmed that the PCR products corresponded to the expected RGS targets (not shown). A comparison of RGS expression levels for the different pregnancy states is shown in Fig. 2. RGS2 and RGS5 were the most abundantly expressed mRNAs in each of the patient groups, but we also detected transcripts for RGS1, RGS4, RGS9, RGS10, RGS12, RGS13, RGS14 and RGS16. Expression of RGS4 and RGS16, and to a lesser extent RGS14, increased in the term labouring samples compared to all other sample groups. Expression of RGS2 was also increased in the term labouring samples relative to the preterm and term non-labouring samples, but was not significantly increased relative to the non-pregnant group.

\subsection{Interactions of RGS proteins with G protein-coupled receptors}

RGS proteins are divided into subfamilies based on sequence homology and RGS2 and RGS5 (as well as RGS4 and RGS16) belong to the R4 family (Abramow-Newerly et al., 2006; Bansal et al., 2007). The R4 family members are the smallest and best 
characterised of the RGS proteins. They are generally non-discriminatory in vitro and act as GAPs on both Gaq/11 and Gai/o (De Vries et al., 2000). In contrast, they display much greater specificity in intact cells and it has been suggested that part of this specificity is due to direct interactions between the RGS proteins and their target receptors (reviewed by Neitzel and Hepler, 2006). RGS proteins have been documented to bind to $\mathrm{G}$ protein-coupled receptors through direct interactions with either the intracellular third (i3) loop (Zeng et al., 1998; Hepler, 2003; Bernstein et al., 2004; Hague et al., 2005) or with the C-terminal tail (Snow et al., 1998; Georgoussi, et al., 2006; Ballon et al., 2006; Langer et al., 2008) of the receptor. The increased expression of RGS2 in cultured human myometrial cells following exposure to oxytocin (Park et al., 2002) is consistent with a role for RGS2 in regulating the myometrial response to oxytocin and we sought to investigate whether RGS2, and RGS5, interact directly with the oxytocin receptor. Our initial experiments utilised the C-terminal tail of the oxytocin receptor since it has been well documented that many $\mathrm{G}$ protein-coupled receptors accessory proteins (e.g. arrestins and $\mathrm{G}$ protein-coupled receptor kinases) bind to this region of receptors (reviewed by Milligan and White, 2001).

The yeast two-hybrid system monitors direct interactions between two proteins, or protein domains (Li and Fields, 1993). Expression of full-length G protein-coupled receptors in this system is complicated by the hydrophobic transmembrane domains and we therefore expressed the C-terminal cytoplasmic tails of the receptors as translational fusions to the GAL4 Binding Domain (Fig. 3). RGS2 and RGS5 are soluble proteins and were expressed as fusions to the GAL4 Activation Domain. Yeast transformants 
expressing each RGS-receptor combination were plated on MM (a defined minimal medium that lacks leucine and tryptophan) to confirm the presence of the two test plasmids, and on MM-His-Ade $+\mathrm{X} \alpha \mathrm{Gal}$ (MM lacking histidine and adenine, but supplemented with 5-bromo-4-chloro-3-indoyl- $\alpha$-D-galactoside) to investigate potential interactions. Control strains expressing the strongly interacting SV40-T antigen and p53, or the non-interacting SV40-T antigen and lamin-C, were included for comparison. Interaction between the two target proteins recombines the GAL4 Binding and Activation Domains, leading to expression of the $H I S 3, A D E 2$ and $M E L 1$ reporter genes and the formation of blue colonies on the test plates. The results suggest an interaction between the oxytocin receptor and both RGS2 and RGS5 (Fig. 3). We were unable to observe any interaction between the i3 loops of either the oxytocin receptor or the CRF receptor with the RGS proteins tested (data not shown). To provide a more quantitative measurement of the strength of the interactions, liquid-based $\beta$-galactosidase assays were performed on all transformants to measure expression of the $L a c Z$ reporter gene. Under the conditions used, a strong interaction between two proteins (such as SV40-T antigen and p53) generates $\sim 4.5$ Units of $\beta$-galactosidase activity, while two non-interacting proteins (such as SV40-T antigen and lamin C) generate less than 0.5 Units. Strains expressing the oxytocin receptor generated more than 3 Units of activity with both RGS2 and RGS5, suggesting strong interactions. The lack of interaction between the oxytocin receptor and RGS1, and between any of the RGS proteins and the CRF receptor, suggests that the interactions of the oxytocin receptor with RGS2 and RGS5 are specific. 
The yeast two-hybrid data indicated that the oxytocin receptor interacted with both RGS2 and RGS5, and we sought to determine whether these proteins also interacted in human myometrial cells. Immunoblotting demonstrated expression of the oxytocin receptor, CRF receptor, RGS2 and RGS5 in human primary myometrial cells (Fig. 4). To investigate co-immunoprecipitation of RGS proteins with G protein-coupled receptors, cell extracts were incubated with a pre-immune antibody or antibodies specific for the oxytocin or CRF receptors and immunocomplexes recovered on protein G-Sepharose beads, eluted in sample buffer, and resolved by SDS-PAGE. Samples were transferred to a PVDF membrane and probed with antibodies to either RGS2 or RGS5.

Immunocomplexes isolated using the antibody to the oxytocin receptor contained both RGS2 and RGS5, indicating that these proteins probably interact within intact cells (Fig. 4). In contrast, neither RGS2 nor RGS5 were present in immunocomplexes isolated using the antibody to the CRF receptor. 


\section{Discussion}

We report the first comprehensive analysis of RGS expression in human myometrium at different stages of pregnancy. RGS2 and RGS5 were highly expressed in all samples, while expression of RGS4, RGS14 and RGS16 increased in the term labouring samples. RGS2 levels were higher in the term labouring samples than in the preterm and term nonlabouring samples, although it was also relatively high in the non-pregnant sample. Transcripts for RGS1, RGS9, RGS10, RGS12 and RGS13 were detected at low levels in all samples.

A recent microarray analysis comparing transcriptional profiles of human myometrium at term pregnancy compared with that at labour observed a $>5$-fold increase in RGS12 mRNA in the labouring sample (expression levels for the other RGS proteins were not reported) (O'Brien et al., 2008). Why this is different to our findings for RGS12 remains unclear. The only other analysis of RGS expression in myometrium considered only RGS2, showing an increase in mRNA levels in cultured human myometrial cells following stimulation with oxytocin (Park et al., 2002), and an increase in mRNA levels during pregnancy in rats (Suarez et al., 2003). Although of interest, neither study is directly comparable to our results on RGS expression.

Our observations that RGS2, RGS4, RGS14 and RGS16 are increased in the term labouring samples are particular interesting given the potential physiological roles that these RGS proteins may play within cells. It has been documented that RGS2, RGS4 and 
RGS16 all negatively regulate signalling mediated by Gaq/11 and Gai/o (Hepler, 2003; Willars, 2006; Ladds et al., 2007). Given that the oxytocin receptor has been shown to couple to both these classes of G protein (Sanborn et al., 1995; Phaneuf et al., 1995), it is tempting to speculate that the up regulation of these RGS proteins is required to terminate the labouring process. Further, evidence has emerged that some RGS proteins play positive regulatory roles within signalling. For example, it has been demonstrated that expression of RGS proteins can significantly increase the receptor-stimulated activation of both $\mathrm{K}^{+}$and $\mathrm{Ca}^{2+}$ channels (Tinker, 2008). It is therefore plausible to suggest that the up regulation, at term, of these RGS proteins, results in increased flux of $\mathrm{Ca}^{2+}$ ions thereby potentially promoting uterine contractions. Further studies, utilising RGS proteins with modified activities, (either dominant negative (Bansal et al., 2007) or gain-offunction (Hill et al., 2008)) will be required to elucidate the precise role that each RGS protein performs in the labouring process.

RGS2 and RGS5 belong to the R4 subfamily of RGS proteins (Abramow-Newerly et al., 2006), members of which are believed to interact directly with their target receptors (Xu et al., 1999; Wang et al., 2002; Cho et al., 2003; Benians et al., 2005). Yeast two-hybrid analysis and co-immunoprecipitation using extracts from primary myometrial cells confirmed that both RGS2 and RGS5 interacted with the oxytocin receptor. Neither RGS2 nor RGS5 interacted with the CRF receptor. Although there are several reports of the interaction of RGS2 with various G protein-coupled receptors (Hepler, 2003; Zeng et al., 1998; Bernstein et al., 2004; Hague et al., 2005), we believe this is the first time that RGS5 has been shown to interact directly with a receptor. 
The interaction between RGS2 and the oxytocin receptor is particularly encouraging given that expression of RGS2 is upregulated in response to stimulation with oxytocin (Park et al., 2002). Taken together, the results are very suggestive that RGS2 may be important in regulating the myometrial response to oxytocin. A similar proposal could also be made for RGS5, and it will be interesting to discover if any of the other RGS proteins expressed in the myometrium also interact with $\mathrm{G}$ protein-coupled receptors. Another challenge will be to investigate whether these interactions have any consequence on the contractile state of the human myometrium. We are encouraged by their ability to regulate contraction in cardiomyocytes (Tamirisa et al., 1999; Mittmann et al., 2002;

Snabaitis et al., 2005; Hao et al., 2006), vascular smooth muscle cells (Tang et al., 2003) and intestinal smooth muscle (Hu et al., 2008). 


\section{References}

Abramow-Newerly, M., Roy, A.A., Nunn, C., Chidiac, P. 2006. RGS proteins have a signalling complex: interactions between RGS proteins and GPCRs, effectors, and auxiliary proteins. Cell. Signal. 18, 579-591.

Bansal, G., Druey, K.M., Xie, Z. 2007. R4 RGS proteins: Regulation of G-protein signaling and beyond. Pharmacol. Therap. 116, 473-495.

Benians, A., Nobles, M., Hosny, S. Tinker, A. 2005. Regulators of G-protein signaling form a quaternary complex with the agonist, receptor, and G-protein. A novel explanation for the acceleration of signaling activation kinetics. J. Biol. Chem. 280, 13383-13394.

Bernstein, L.S., Ramineni, S., Hague, C., Cladman, W., Chidiac, P., Levey, A.I., Hepler, J.R. 2004. RGS2 binds directly and selectively to the M1 muscarinic acetylcholine receptor third intracellular loop to modulate $\mathrm{G}_{\mathrm{q} / 11} \alpha$ signaling. J. Biol. Chem. 279, 21248-21256.

Blanks, A.M., Thornton, S. 2003. The role of oxytocin in parturition. BJOG 20, 46-51. Ballon, D.R., Flanary, P.L., Gladue, D.P., Konopka, J.B., Dohlman, H.G., Thorner, J. 2006. DEP-domain-mediated regulation of GPCR signaling responses. Cell. 126, 107993.

Brodt-Eppley, J., Myatt, L. 1999. Prostaglandin receptors in lower segment myometrium during gestation and labor. Obstet. Gynecol. 93, 89-93.

Chatterjee, T.K., Eapen, A.K., Fisher, R.A. 1997. A truncated form of RGS3 negatively regulates $\mathrm{G}$ protein-coupled receptor stimulation of adenylyl cyclase and 
phosphoinositide phospholipase C. J. Biol. Chem. 272, 15481-15487.

Cho, H., Harrison, K., Schwartz, O., Kehrl, J.H. 2003. The aorta and heart differentially express RGS (regulators of G-protein signalling) proteins that selectively regulate sphingosine 1-phosphate, angiotensin II and endothelin-1 signalling. Biochem. J. 371, 973-980.

De Vries, L., Zheng, B., Fischer, T., Elenko, E., Farquhar, M.G. 2000. The regulator of G protein signaling family. Annu. Rev. Pharmacol. Toxicol. 40, 235-271.

Dohlman, H.G., Song, J.P., Ma, D.R., Courchesne, W.E., Thorner, J. 1996. SST2, a negative regulator of pheromone signalling in the yeast Saccharomyces cerevisiae: expression, localisation and genetic interaction and physical association with GPA1 (the G protein $\alpha$ subunit). Mol. Cell. Biol. 16, 5194-5209.

Druey, K.M., Blumer, K.J., Kang, V.H., Kehrl, J.H. 1996. Inhibition of G proteinmediated MAP kinase activation by members of a novel mammalian gene family. Nature 379, 742-746.

Europe-Finner, G.N., Phaneuf, S., Cartwright, E., Mardon, H.J., López Bernal, A. 1997. Expression of human myometrial Gas messenger ribonucleic acid transcript during pregnancy and labour: involvement of alternative splicing pathways. J. Mol. Endocrinol. 18, 15-25.

Georgoussi, Z., Leontiadis, L., Mazarakou, G., Merkouris, M., Hyde, K., Hamm, H., 2006. Selective interactions between G protein subunits and RGS4 with the C-terminal domains of the mu- and delta-opioid receptors regulate opioid receptor signaling, Cell. Signal. $18,771-782$ 
Hague, C., Bernstein, L.S., Ramineni, S., Chen, Z., Minneman, K.P., Hepler, J.R. 2005. Selective inhibition of $\alpha 1 \mathrm{~A}$-adrenergic receptor signaling by RGS2 association with the receptor third intracellular loop. J. Biol. Chem. 280, 27289-27295.

Hao, J., Michalek, C., Zhang, W., Zhu, M., Xu, X., Mende, U. 2006. Regulation of cardiomyocyte signaling by RGS proteins: Differential selectivity towards G proteins and susceptibility to regulation. J. Mol. Cell. Cardiology 41, 51-61.

Hill, C., Brownlie, Z., Davey, J., Milligan G., Ladds, G. 2008. Isolation and characterisationof a novel human RGS mutant displaying gain-of-function activity. Cell. Signal. 20, 323-336.

Hepler, J.R. 2003. RGS protein and G protein interactions: a little help from their friends. Mol. Pharmacol. 64, 547-549.

Hollinger, S., Hepler, J.R. 2002. Cellular regulation of RGS proteins: modulators and integrators of G protein signaling. Pharmacol. Rev. 54, 527-559.

Hu, W., Li, F., Mahavadi. S., Murthy, K.S., 2008. Interleukin $1 \beta$ up-regulates RGS4 through the canonical IKK2/kappaB $\alpha / \mathrm{NF}-\mathrm{kappaB}$ pathway in rabbit colonic smooth muscle. Biochem. J. 412, 35-43.

Koelle, M.R., Horvitz, H.R. 1996. EGL-10 regulates G protein signaling in the C. elegans nervous system and shares a conserved domain with many mammalian proteins. Cell $84,115-125$

Ladds, G., Goddard, A., Hill, C., Thornton, S., Davey, J. 2007 Differential effects of RGS proteins on $\mathrm{G} \alpha_{\mathrm{q}}$ and $\mathrm{G} \alpha_{11}$ activity. Cell. Signal. 19, 103-113. 
Langer, I., Tikhonova, I.G., Boulegue, C., Esteve, J.P., Vatinel, S., Ferrand, A., Moroder, L., Robberecht, P., Fourmy, D. 2008. Evidence for a direct and functional interaction between the regulators of $\mathrm{G}$ protein. doi:10.1124/mol.108.051607.

signaling-2 and phosphorylated C-terminus of cholecystokinin-2 receptor

Li, B. Fields, S. 1993. Identification of mutations in p53 that affect its binding to SV40 T antigen by using the yeast two-hybrid system. FASEB J. 7, 957-963.

Lopez-Bernal, A.L., TambyRaja, R.L. 2000. Preterm Labour. Baillieres Best Pract. Res. Clin. Obstet. Gynaecol. 14, 133-153.

Mittmann, C., Chung, C.H., Höppner, G., Michalek, C., Nose, M., Schüler, C., Schuh, A., Eschenhagen, T., Weil, J., Pieske, B., Hirt, S., Wieland, T. 2002. Expression of ten RGS proteins in human myocardium: functional characterization of an upregulation of RGS4 in heart failure. Cardiovasc. Res. 55, 778-786.

Moore, S.D., Brodt-Eppley, J., Cornelison, L.M., Burk, S.E., Slater, D.M. Myatt, L. 1999. Expression of prostaglandin $\mathrm{H}$ synthase isoforms in human myometrium at parturition. Am. J. Obstet. Gynecol. 180, 103-109.

Neitzel, K.L., Hepler, J.R. 2006. Cellular mechanisms that determine selective RGS protein regulation of G protein-coupled receptor signaling. Semin. Cell Dev. Biol. 17, 383-389.

O’Brien, M., Morrison, J.J., Smith, T.J., 2008. Upregulation of PSCDBP, TLR2, TWIST1, FLJ35382, EDNRB and RGS12 gene expression in human myometrium at labor. Reprod. Sci. 15, 382-393.

Park, E.S., Echetebu, C.O., Soloff, S., Soloff, M.S. 2002. Oxytocin stimulation of RGS2 mRNA expression in cultured human myometrial cells. Am. J. Physiol. Endocrinol. 
Metab. 282, E580-E584.

Phaneuf, S., Europe-Finner, G.N., Carrasco, M.P., Hamilton, C.H., López Bernal, A. 1995. Oxytocin signalling in human myometrium. Adv. Exp. Med. Biol. 395, 453-467. Plested, C.P., Lopez-Bernal, A.L. 2001. Desensitisation of the oxytocin receptor and other G protein coupled receptors in the human myometrium. Exp. Physiol. 86, 303312.

Ross, E.M., Wilkie, T.M. 2000. GTPase-activating proteins for heterotrimeric G proteins: regulators of G protein signaling (RGS) and RGS-like proteins. Annu. Rev. Biochem. $69,795-827$.

Saitoh, O., Kubo, Y., Miyatani, Y., Assano, T., Nakata, H. 1997. RGS8 accelerates Gprotein-mediated modulation of $\mathrm{K}^{+}$currents. Nature 390, 525-529.

Sanborn, B., Qian, A., Ku, C., Wen, Y., Anwer, K., Monga, M., Singh, S. 1995. Mechanisms regulating oxytocin receptor coupling to phospholipase $\mathrm{C}$ in rat and human myometrium. Adv. Exp. Med. Biol. 395, 469-479.

Snabaitis, A.K., Muntendorf, A., Wieland, T., Avkiran, M. 2005. Regulation of the extracellular signal-regulated kinase pathway in adult myocardium: differential roles of $\mathrm{G}(\mathrm{q} / 11)$, $\mathrm{Gi}$ and $\mathrm{G}(12 / 13)$ proteins in signalling by alpha1-adrenergic, endothelin-1 and thrombin-sensitive protease-activated receptors. Cell. Signal. 17, 655-664.

Snow, B.E., Hall, R.A., Krumins, A.M., Brothers, G.M., Bouchard, D., Brothers, C.A., Chung, S., Mangion, J., Gilman, A.G., Lefkowitz, R.J., Siderovski, D.P. 1998. GTPase activating specificity of RGS12 and binding specificity of an alternatively spliced PDZ (PSD-95/Dlg/ZO-1) domain. J. Biol. Chem. 273, 17749-17755.

Suarez, V.R., Park, E-S., Hankins, G.D.V., Soloff, M.S. 2003. Expression of regulator of 
G protein signaling-2 (RGS2) in rat myometrium during pregnancy and parturition. Am. J. Obstet. Gynecol. 188, 973-977.

Tamirisa, P., Blumer, K.J., Muslin, A.J. 1999. RGS4 inhibits G-protein signaling in cardiomyocytes. Circulation 99, 441-447.

Tang, K.M., Wang, G.R., Lu, P., Karas, R.H., Aronovitz, M., Heximer, S.P., Kaltenbronn K.M., Blumer, K.J., Siderovski, D.P., Zhu, Y., Mendelsohn, M.E. 2003. Regulator of G protein signaling-2 mediates vascular smooth muscle relaxation and blood pressure. Nature Medicine 12, 1506-1512.

Tinker, A. 2006. The selective interactions and functions of regulators of G-protein signalling. Semin. Cell Dev. Biol. 17,377-382.

Tribe, R.M., Moriaty, P., Poston, L. 2000. Calcium homeostatic pathways change with gestation in human myometrium. Biol. Reprod. 63, 748-755.

Wang, Q., Liu, M., Mullah, B., Siderovski, D.P., Neubig, R.R. 2002. Receptor-selective effects of endogenous RGS3 and RGS5 to regulate mitogen-activated protein kinase activation in rat vascular smooth muscle cells. J. Biol. Chem. 277, 24949-24958.

Willars, G.B. 2006. Mammalian RGS proteins: multifunctional regulators of cellular signaling. Semin. Cell Dev. Biol. 17, 363-376.

Xie, G.X. Palmer, P.P. 2007. How regulators of G protein signaling achieve selective regulation. J. Mol. Biol. 366, 349-365.

Xu, X., Zeng, W., Popov, S., Berman, D.M., Davignon, I., Yu, K., Yowe, D., Offermanns, S., Muallem, S., Wilkie, T.M. 1999. RGS proteins determine signaling specificity of Gq-coupled receptors. J. Biol. Chem. 274, 3549-3556.

Zeng, W., Xu, X., Popov, S., Mukhopadhyay, S., Chidiac, P., Swistok, J., Danho, W., 
Yagaloff, K.A., Fisher, S.L., Ross, E.M., Muallem, S., Wilkie, T.M. 1998. The Nterminal domain of RGS4 confers receptor-selective inhibition of G protein signaling. J. Biol. Chem. 273, 34687-34690. 


\section{Acknowledgments}

This work was supported by Wellbeing (Project Grant 2198, ST and JD) and the University Hospitals of Coventry and Warwickshire NHS Trust (GL and ST). We thank the patients and staff at Women's Hospital, University Hospitals of Coventry and Warwickshire, Coventry for their help in collecting myometrial biopsies. In particular, we thank Jane Green who supervised sample collection. 
Figure and Table legends

\section{Fig. 1 RGS expression in human myometrium}

Semi-quantitative RT-PCR was used to monitor expression of RGS1 to RGS16 in human myometrium. The expression of each RGS protein was compared to that of calponin, an internal standard which remains unchanged with and during pregnancy. Profiles from the four different study groups are shown: non-pregnant $(n=4)$; pregnant preterm $(n=4, w$ indicates the duration of the pregnancy in weeks), term pregnant non-labouring $(n=5)$ term pregnant labouring $(\mathrm{n}=5)$. Patients' numbers are show for reference. The results shown are the means of three independent determinations.

\section{Fig. 2 RGS expression at different stages of pregnancy}

Expression levels for the various RGS proteins in the different sample groups (expressed as mean $\pm \mathrm{SE}$ ) were analysed by one-way ANOVA with Tukey's multiple comparison test. Differences were considered significant as follows; $* P<0.05$, ** $P<0.01$, *** $P<0.005$.

\section{Fig. 3 Two-hybrid analysis of RGS-G protein-coupled receptor interactions} Various combinations of RGS proteins (expressed from pGADT7) and the C-terminal cytoplasmic tail regions of the oxytocin receptor (OTR) or corticotrophin releasing factor receptor 1a (CRFR) (expressed from pGBKT7) were analysed in the yeast two-hybrid system. All transformants grew on MM, but only those containing interacting proteins are able to grow on MM-His-Ade+XaGal, suggesting an interaction between the oxytocin receptor and both RGS2 and RGS5. A liquid-based $\beta$-galactosidase assay provided a quantitative measure of the strength of the various interactions. The results are shown as 
means \pm SE of triplicate determinations. Strains expressing the strongly interacting combination of SV40-T antigen and p53, and the non-interacting combination of SV40-T antigen and lamin-C were included for comparisons.

Fig. 4 RGS2 and RGS5 interact with the oxytocin receptor in human myometrial cells

(A) Protein extracts generated from human primary myometrial cells were resolved by SDS-PAGE and immunoblot analysis confirmed expression of the CRF receptor (CRFR), oxytocin receptor (OTR), RGS2 and RGS5. (B) The cell extracts from A were incubated with a preimmune antibody or antibodies specific for the CRF receptor (anti-CRFR) or oxytocin receptor (anti-OTR), and immunocomplexes recovered on protein G-Sepharose beads, eluted in sample buffer, and resolved by SDS-PAGE. Immunoblot analysis confirmed the presence of RGS2 and RGS5 in the extracts (track labelled 'lysate') and revealed co-immunoprecipitation of RGS2 and RGS5 with the oxytocin receptor but not the CRF receptor.

Table 1 Oligonucleotide primer sequences for human RGS1 to RGS16

Sequences for the Sense (S) and Antisense (A) primers for each RGS protein are shown with upper case letters representing sequences from within each RGS target and lower case letters representing sequences included to allow cloning of the PCR products. Accession numbers (Acc No) are given for each RGS, and the expected sizes of the various PCR products. 
Figure 1
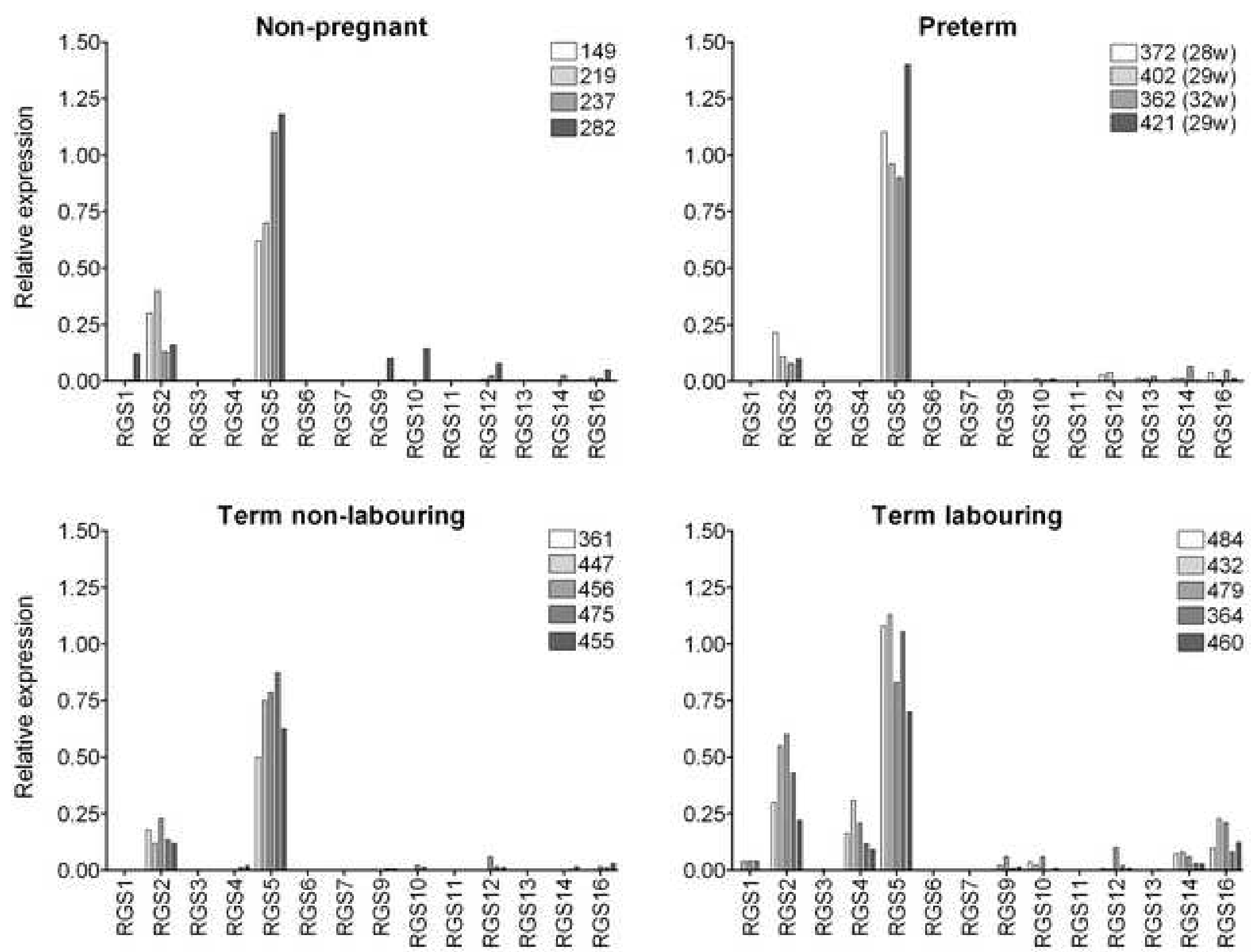


\section{Figure 2}

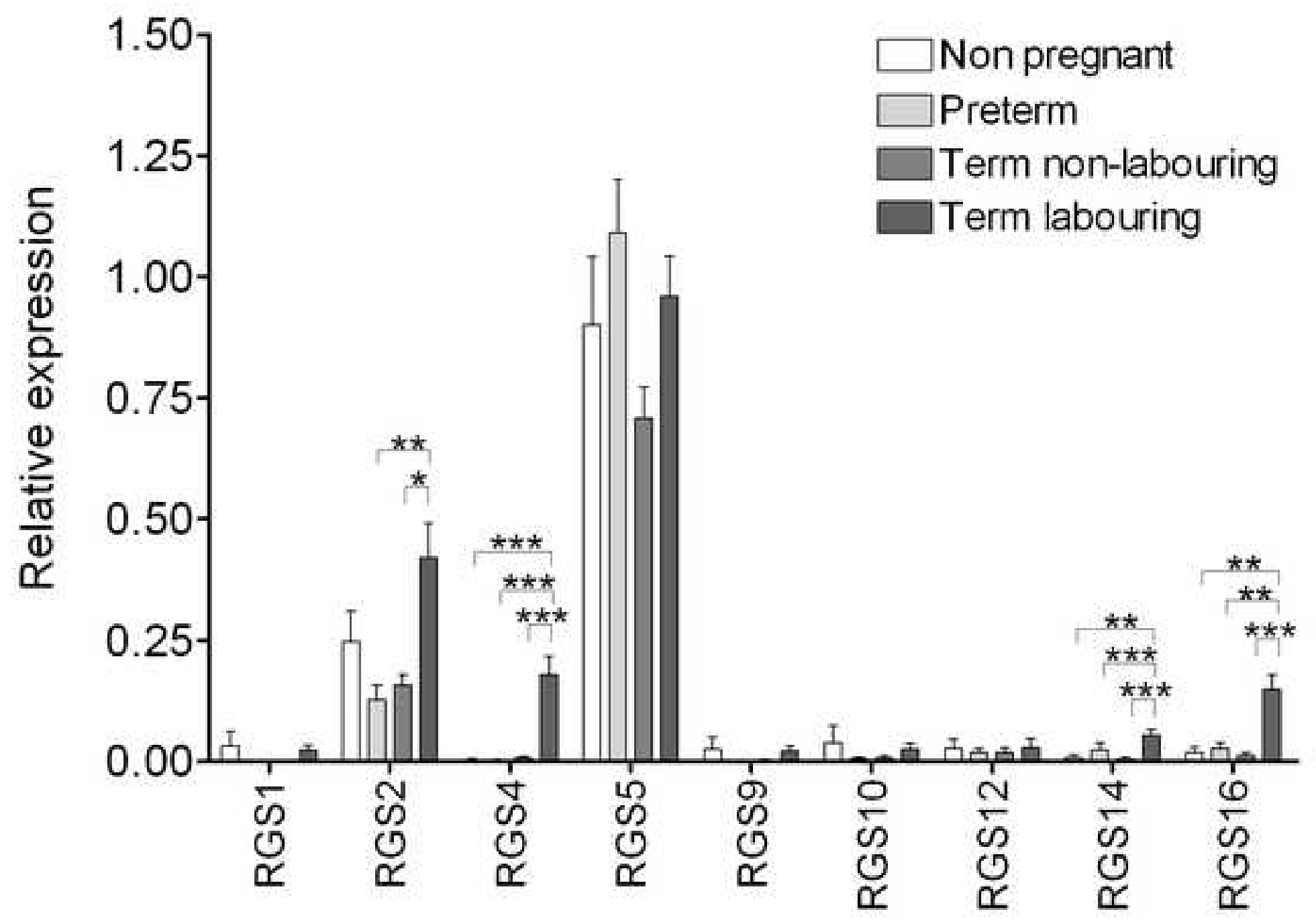


Figure 3

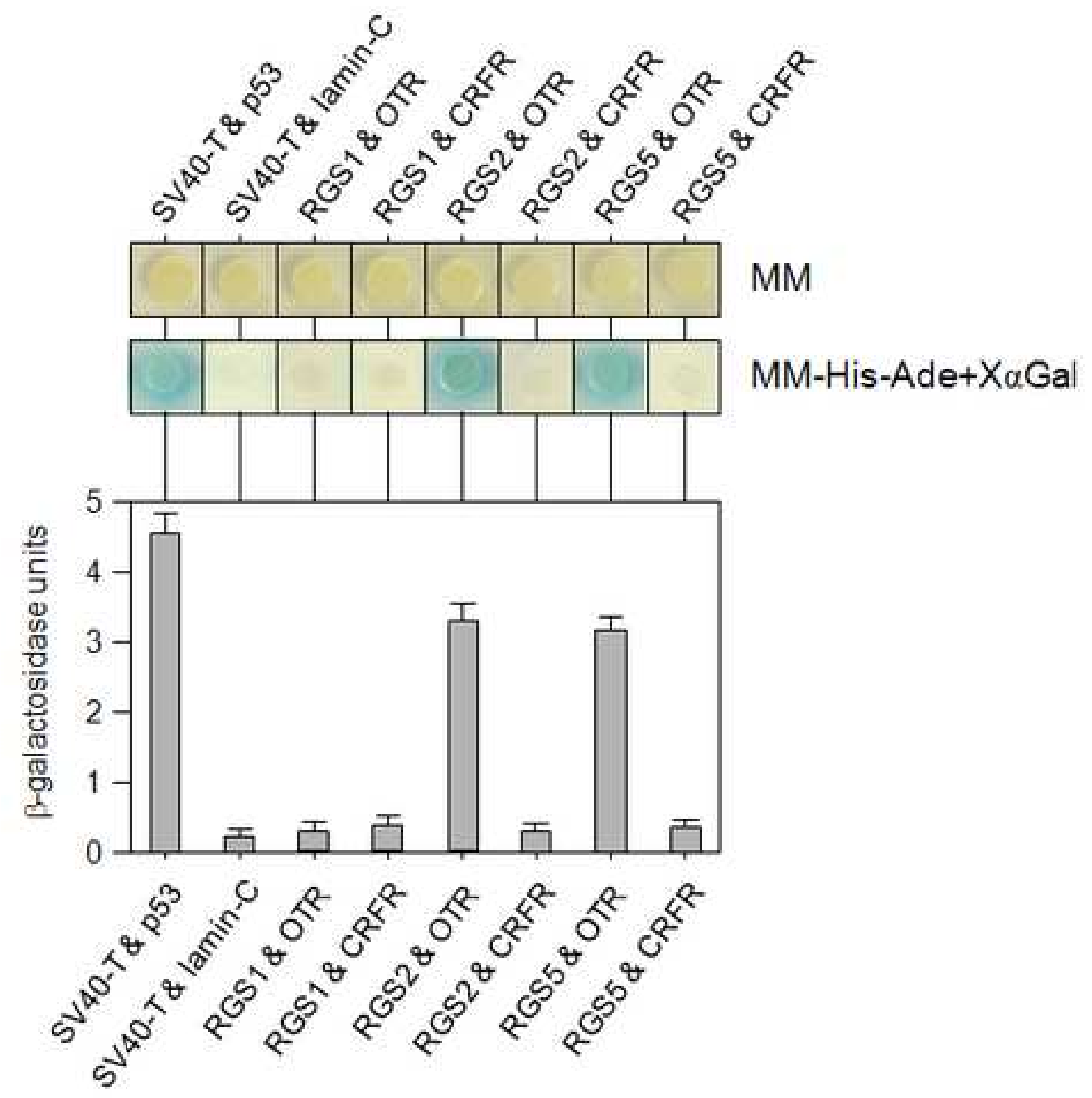


Click here to download high resolution image

Figure 4

A

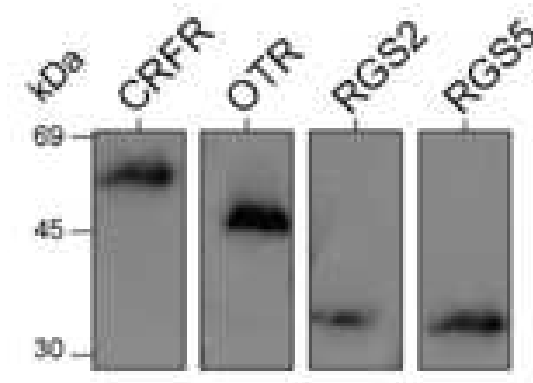

B

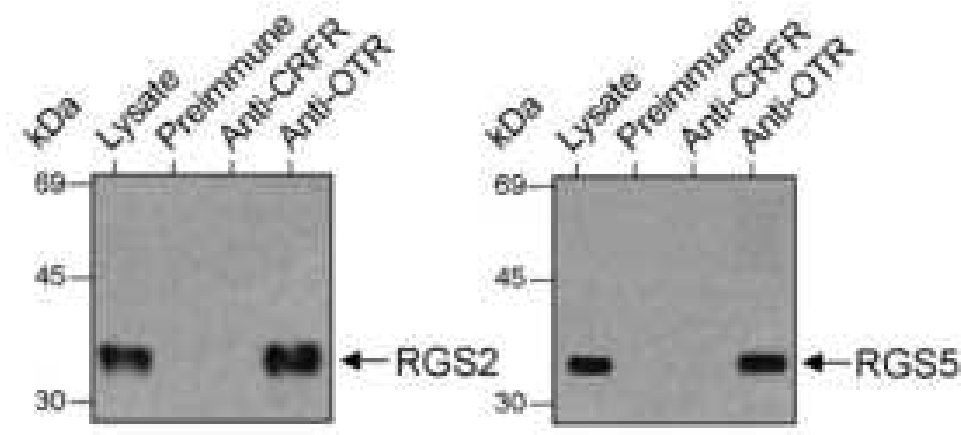


Table 1 Oligonucleotide primer sequences for human RGS1 to RGS16

\begin{tabular}{|c|c|c|c|c|}
\hline RGS & Acc No & $\begin{array}{l}\text { Primer } \\
\text { name }\end{array}$ & Primer sequence & Size (bp) \\
\hline RGS1 & $\mathrm{X} 73427.1$ & $\begin{array}{l}\text { JO910 (S) } \\
\text { JO911 (A) }\end{array}$ & $\begin{array}{l}\text { ggggatccgtATGCCAGGAATGTTCTTCTCTGC } \\
\text { ggggatccTCACTTTAGGCTATTAGCCTGC }\end{array}$ & 591 \\
\hline RGS2 & L13391 & $\begin{array}{l}\mathrm{JO} 1339(\mathrm{~S}) \\
\mathrm{JO} 1340(\mathrm{~A})\end{array}$ & $\begin{array}{l}\text { ggggatccgtATGCAAAGTGCTATGTTCTTGGC } \\
\text { ggggatccTCATGTAGCATGAGGCTCTGTGG }\end{array}$ & 636 \\
\hline RGS3 & U27655 & $\begin{array}{l}\text { JO915 (S) } \\
\text { JO916(A) }\end{array}$ & $\begin{array}{l}\text { ggggatccCTAAAGCGGGGGACTCATCTTC } \\
\text { ggggatccaccATGCACCACCTTTCССТCTTC }\end{array}$ & 620 \\
\hline RGS4 & U27768 & $\begin{array}{l}\text { JO917 (S) } \\
\text { JO918 (A) }\end{array}$ & $\begin{array}{l}\text { ggggatccgtATGTGCAAAGGGCTTGCAGGTC } \\
\text { ggggatccTTAGGCACACTGAGGGACCAG }\end{array}$ & 618 \\
\hline RGS5 & AF030108 & $\begin{array}{l}\mathrm{JO} 1314(\mathrm{~S}) \\
\mathrm{JO} 1315(\mathrm{~A})\end{array}$ & $\begin{array}{l}\text { gggggatccgtATGTGCAAAGGACTTGCAGC } \\
\text { gggggatccCTACTTGATTAACTCCTGATAAAACT }\end{array}$ & 546 \\
\hline RGS6 & O75576 & $\begin{array}{l}\mathrm{JO} 1316(\mathrm{~S}) \\
\mathrm{JO} 1318(\mathrm{~A})\end{array}$ & $\begin{array}{l}\text { gggggatccgtATGGCTCAAGGGTCCGGGGATC } \\
\text { gggggatccTCAGGGCCTCTTAGCGAGTGG }\end{array}$ & 513 \\
\hline RGS7 & U32439 & $\begin{array}{l}\mathrm{JO} 1319(\mathrm{~S}) \\
\mathrm{JO} 1320(\mathrm{~A})\end{array}$ & $\begin{array}{l}\text { gggggatccGCCACCTGACCCTTCTAACCCATG } \\
\text { gggggatccTTAGTAAGACTGAGCAAGGCTTG }\end{array}$ & 516 \\
\hline RGS9 & AF071476 & $\begin{array}{l}\text { JO1321 (S) } \\
\text { JO1322(A) }\end{array}$ & $\begin{array}{l}\text { gggggatccgtATGACAATCCGACACCAAGGCC } \\
\text { gggggatccATCGGTGCACCAGCCAGTATGCC }\end{array}$ & 577 \\
\hline RGS10 & AF045229 & $\begin{array}{l}\mathrm{JO} 1324(\mathrm{~S}) \\
\mathrm{JO} 1325(\mathrm{~A})\end{array}$ & $\begin{array}{l}\text { gggggatccgtATGGAACACATCCACGACAGCG } \\
\text { gggggatccTCATGTGTTATAAATTCTGGAAGC }\end{array}$ & 504 \\
\hline RGS11 & AB016929 & $\begin{array}{l}\mathrm{JO} 1326(\mathrm{~S}) \\
\mathrm{JO} 1327(\mathrm{~A})\end{array}$ & $\begin{array}{l}\text { gggagatctgtATGGCCGCCGGCCCCGCGCCG } \\
\text { gggagatctCCTGGCACGCAATGACCAGCCTG }\end{array}$ & 523 \\
\hline RGS12 & O14924 & $\begin{array}{l}\mathrm{JO} 1329(\mathrm{~S}) \\
\mathrm{JO} 1330(\mathrm{~A})\end{array}$ & $\begin{array}{l}\text { gggggatCCTGCGTGAGAGGAGGGTCGCCAGC } \\
\text { gggggaTCCGCTTCTTCTCGCTGTCCTC }\end{array}$ & 571 \\
\hline RGS13 & O14921 & $\begin{array}{l}\mathrm{JO} 1333(\mathrm{~S}) \\
\mathrm{JO} 1334(\mathrm{~A})\end{array}$ & $\begin{array}{l}\text { gggggatccgtATGAGCAGGCGGAATTGTTGGATTT } \\
\text { gggggatccTCAGAAACTGTTGTTGGACTGC }\end{array}$ & 480 \\
\hline RGS14 & O43566 & $\begin{array}{l}\mathrm{JO} 1335(\mathrm{~S}) \\
\mathrm{JO} 1336(\mathrm{~A})\end{array}$ & $\begin{array}{l}\text { gggggatcCATGTTTCGGGCACAGCAGCTTCAG } \\
\text { gggggatcCATGTCTCGGATGGTGAGGCCAGG }\end{array}$ & 523 \\
\hline RGS16 & O15492 & $\begin{array}{l}\mathrm{JO} 1337(\mathrm{~S}) \\
\mathrm{JO} 1338(\mathrm{~A})\end{array}$ & $\begin{array}{l}\text { gggggatccaCCATGTGCCGCACCCTGGCCGCC } \\
\text { gggggatcCTCAGGTGTGTGAGGGCTCGTCC }\end{array}$ & 612 \\
\hline
\end{tabular}

